\title{
BOOKS
}

\section{Practical guide to AIDS home care}

AIDS Care at Home, by Judith Greif and Beth Ann Golden (1994). John Wiley and Sons Canada Inc, 22 Worcester Road, Rexdale, Ontario M9W 1L1. ISBN 0471-58468-1, 360 pages.

This book is designed for caregivers of individuals living with the day to day reality of the human immunodeficiency virus (HIV) and AIDS.

It is a practical guide that covers basic pathophysiology, how to make the home safe, managing symptoms and dealing with the multiple emotional issues around providing care at home.

Throughout the section on managing symptoms, there are basic definitions, specific symptoms, what to look for for example, weight loss (look for things such as clothing seemingly too big, actual weight loss on the scale) - what to do and what not to do, and when to consult your doctor. There are also practical suggestions on how to use items in the home, for example, how to wash hair with the person in bed.

This is an American book, so the resources listed in appendix $G$ do not include Canadian ones. That information may be found in the Canadian manual entitled Living with Dying - Dying at Home: An AIDS Care Team Resource Manual published in 1994 and available through the National Aids Clearinghouse at 613-725-3769.

For those wishing to add to a resource library for individuals infected with HIV and for those who provide home care, this book would be an excellent choice.

Anne Russell HIV Nurse Coordinator Health Sciences Centre Winnipeg, Manitoba 


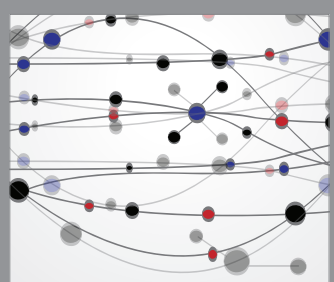

The Scientific World Journal
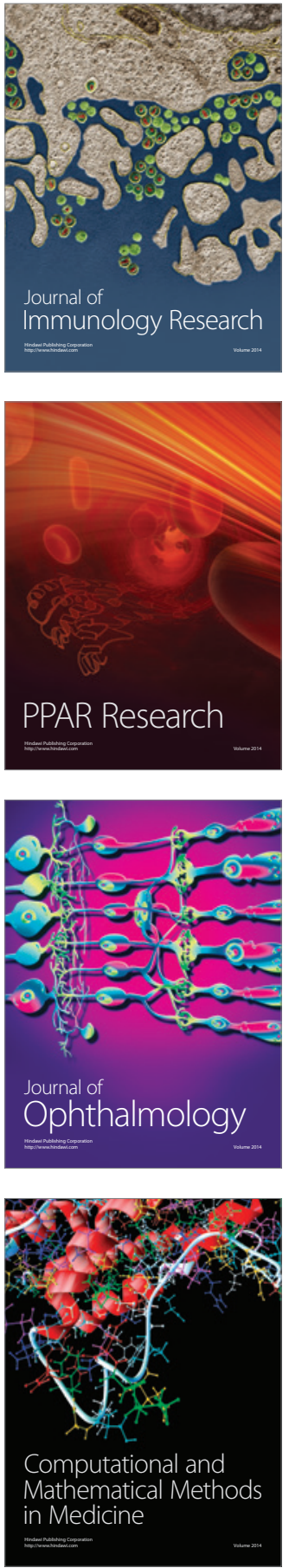

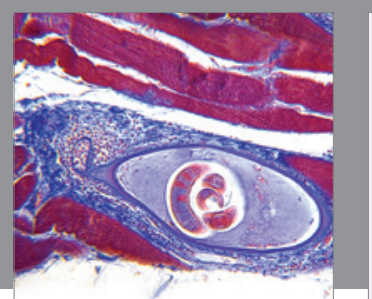

Gastroenterology Research and Practice

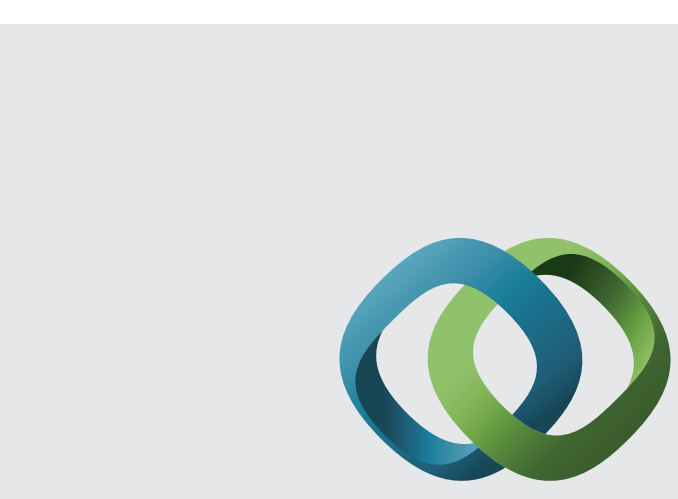

\section{Hindawi}

Submit your manuscripts at

http://www.hindawi.com
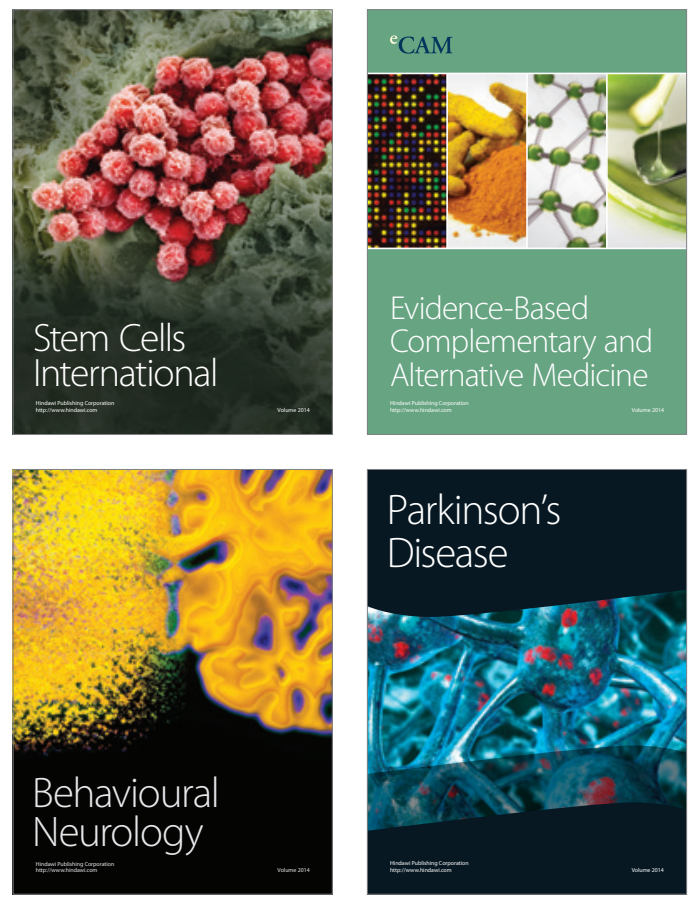
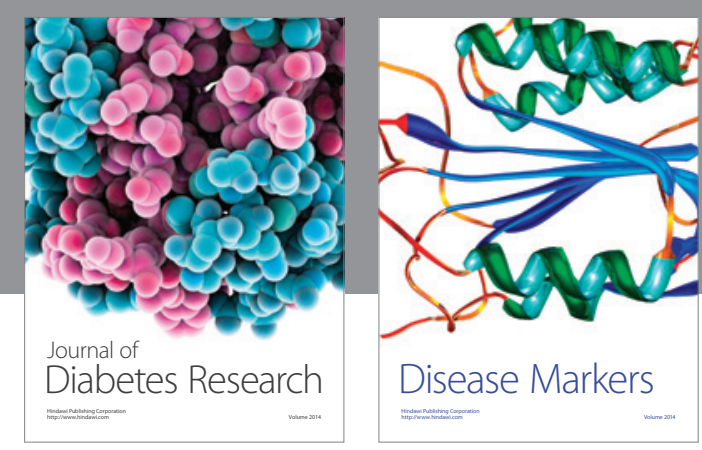

Disease Markers
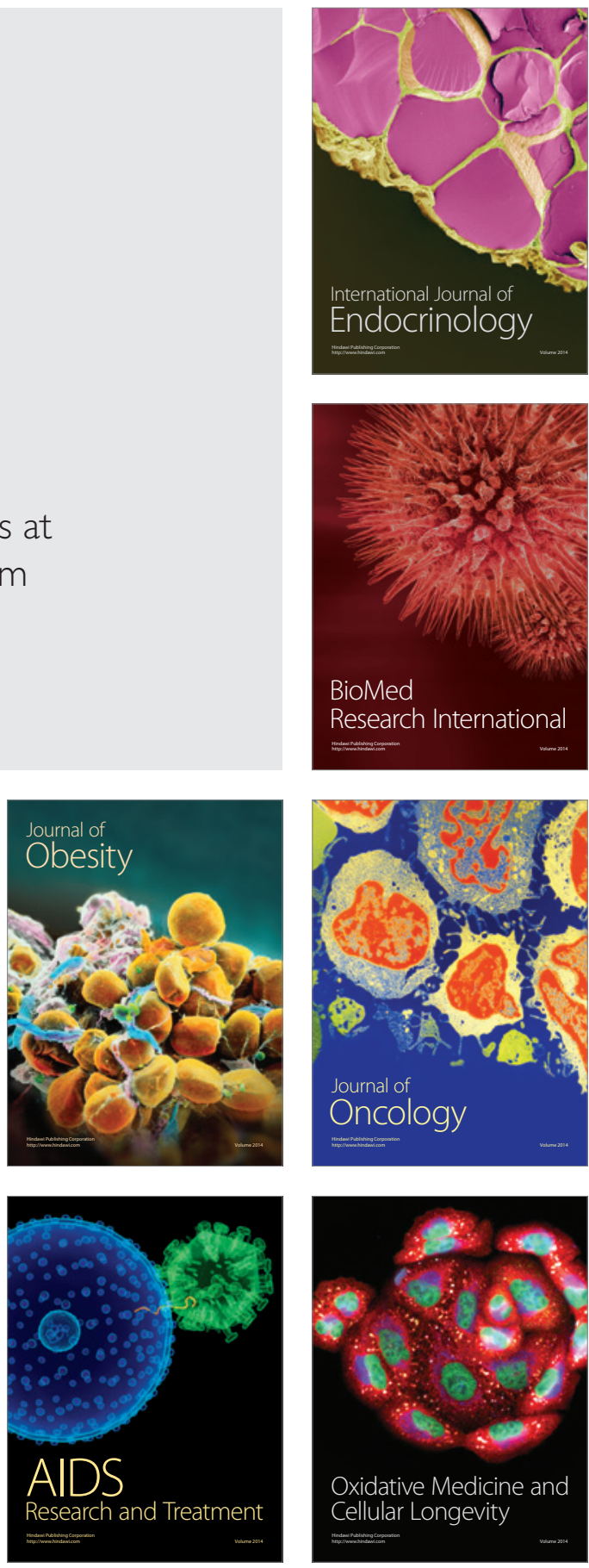